\title{
ESTRATÉGIAS DISCURSIVO-INTERACIONAIS DE CONSTRUÇÃO DE IDENTIDADE DE CONSUMIDOR EM AUDIÊNCIAS DE CONCILIAÇÃO
}

\author{
INTERACTIONAL AND DISCURSIVE STRATEGIES OF IDENTITY \\ CONSTRUCTION OF CONSUMER IN CONCILIATION HEARING
}

\author{
WÂNIA TEREZINHA LADEIRA* \\ ELAINE LUZIA DA SILVA**
}

\begin{abstract}
RESUMO: O presente estudo investiga a construção de identidade que emerge da produção discursiva dos consumidores nas audiências de conciliação de um Juizado Especial Cível de Relações de Consumo de uma cidade mineira. A partir de teorias da Sociolinguística Interacional e da utilização de técnicas da Análise da Conversa, gravamos quatro audiências em áudio e analisamos a construção de identidade de consumidor por meio de seus relatos nas audiências. A análise dos dados confirmou a riqueza de construções identitárias nas narrativas analisadas. Percebemos que os reclamantes constroem suas identidades a fim de se posicionarem como vítimas e posicionarem o seu oponente como vilão. Para isso, as estratégias mais frequentes por eles utilizadas são: a exploração de um grande número de repetições, a utilização de termos extremos e a incorporação de diferentes categorias identitárias.
\end{abstract}

Palavras-chave: Identidade, produção discursiva, audiência de conciliação, estratégias discursivo-interacionais.

\begin{abstract}
This study investigates the construction of identity that emerges in the consumers' discursive production of a conciliation hearing in a kind of Brazilian Small Claim Court (Juizado Especial de Relações de Consumo) in Minas Gerais state. Based on theories of Interactional Sociolinguistic and on Conversation Analyses techniques, we recorded four conciliation hearings and analyzed the identity construction of the consumer through their accounts. The data analysis confirmed the richness of identity construction in the narratives we analyzed. We perceived that consumers construct their identities in order to align themselves in the role of victim and align their opponent in the role of villain. For that, the most used strategies are: the exploration of a great number of repetition, the use of extreme terms, and the incorporation of different identity categories. Keywords: Identity, discursive production, conciliation hearing, interactional and discursive strategies.
\end{abstract}

\section{INTRODUÇÃO}

O presente estudo faz parte de uma pesquisa maior sobre interação em audiências de conciliação de um juizado especial de relações de consumo (LADEIRA, 2005). A partir de teorias da Sociolinguística Interacional, enfatizamos a construção de identidade de consumidor que emerge da fala em interação nessas audiências. Utilizando técnicas da Análise da Conversa, gravamos quatro audiências em áudio e analisamos a construção de

\footnotetext{
* UFV, Viçosa (MG), Brasil. wania.ladeira@ufv.br

** Mestranda em Estudos Linguísticos, UFV, Viçosa (MG), Brasil. elaineufv@yahoo.com.br
} 
identidade de consumidor por meio de certas estratégias discursivo-interacionais usadas nos relatos, nas audiências.

No presente estudo, o conceito de identidade se refere a uma construção dinâmica do "eu", apresentada nos diversos episódios e interações sociais. Como lembra Berger \& Luckmann (1985), é no contexto de interação, sobretudo face a face, que os interagentes trocam pistas verbais e não-verbais (GUMPERZ, 1998) que permitem formar tipificações recíprocas. Segundo Littlejohn (1982), as pessoas empenhadas em uma interação face a face estabelecem e mantêm uma relação definida por percepções mútuas em um processo de interdependência comunicativa, no qual, segundo Goffman (1999; 1980), elas se apresentam às outras manobrando impressões a fim de manterem determinada linha ou face.

Durante a construção do relato do conflito, processo que sempre ocorre em audiências de conciliação em juizados, o posicionamento do consumidor e as suas estratégias de elaboração de face sugerem manobras de um "eu" desacreditado na interação. Assim, o consumidor se constrói através de relatos exagerados, utilizando estratégias altamente persuasivas, tais como: formulação extrema, autocategorização na posição de vítima e categorização do outro como culpado.

Este texto é composto basicamente de uma sessão teórica e de uma sessão de análise. $\mathrm{Na}$ primeira, fazemos algumas considerações sobre o uso de narrativas em interações mediadas por uma terceira parte. Na segunda, apresentamos a análise na qual as estratégias discursivo-interacionais são utilizadas pelo consumidor, por meio das quais o seu papel de vítima é construído.

\section{IDENTIDADES E NARRATIVAS EM MEDIAÇÃO}

Contar estórias é uma atividade rotineira que aparece nas nossas interações em inúmeras ocasiões. Através de narrativas construímos e coconstruímos a nossa identidade, pois elas apresentam interpretações do passado que dão significado ao mundo que nos cerca (BASTOS, 2008). Do ponto de vista estrutural, a narrativa seria uma sequência de duas ou mais orações em uma juntura temporal, através da qual poderíamos "recapitular e transformar experiências passadas" (LABOV, 1982, p. 224-226). Além disso, uma narrativa deve ter um "ponto", isto é, um motivo pelo qual é contada, conectado ao tópico da conversa. A narrativa também deve ser "contável", ou seja, fazer referência a algo extraordinário. Outra característica importante das narrativas, que, segundo Bastos (2008), não foi identificada nos primeiros trabalhos de Labov seria a credibilidade. Conforme Labov (1982), um evento contável é, definitivamente, incomum. Entretanto, deve ter um mínimo de verossimilhança para que tenha credibilidade. Embora a reportabilidade seja importante para o sucesso de uma narrativa, a credibilidade faz com que ela seja aceita, e não considerada apenas como uma mentira.

A respeito do uso de narrativas em contextos de trabalho, Cobb (1994) e Cobb e Rifkin (1991) têm estudado o uso de narrativas em contextos de mediação. A mediação, na definição de Cobb (1994), seria um processo interativo dentro do qual histórias são produzidas por adversários que contam com uma terceira parte para coordenar a fala em 
Trab. Ling. Aplic., Campinas, 50(1), Jan./Jun. 2011

interação. A narrativa é uma ação discursiva central para se alcançar os objetivos éticos e pragmáticos da mediação.

Cobb e Rifkin (1991) sugerem que as histórias em sessões mediadas seriam representações do passado através das quais identidades, ordem moral e padrões relacionais seriam construídos e negociados, já que as narrativas são estruturas discursivas através das quais pessoas e seus mundos são construídos, isto é, são meios nos quais conflitos emergem e são transformados. Assim, o processo de mediação representaria uma oportunidade de construir histórias, contestá-las e transformá-las.

Para Cobb e Rifkin (1991), todo conflito ou problema tem uma estrutura narrativa, isto é, há um discurso de eventos sequenciados de acordo com uma lógica causal que estabelece papéis para pessoas e direcionam a trama. Como estruturas narrativas, os conflitos demonstram propriedades sistêmicas, de modo que os significados de uma história de conflito são regulados e as interpretações alternativas são limitadas, a fim de obedecer a exigências de coerência interna.

Segundo Cobb (1994), a literatura sobre narrativas se divide em abordagens estruturalistas e pós-estruturalistas. $\mathrm{Na}$ abordagem estruturalista, a narrativa é estudada como estrutura autônoma de contextos sociais, políticos e interativos. Já o pósestruturalismo examina o ato de contar histórias como uma prática, focalizando os desdobramentos da narrativa em interação e a prática do relato como um processo.

A perspectiva pós-estrutural, para Cobb (1994), deve ser preferida no estudo da narrativa em mediações por duas razões: (i) A distinção estrutural entre história factual e discurso não é compatível com a ideologia da mediação, cujo foco não é a representação acurada de eventos reais, mas as diferenças e semelhanças nas formas de representação, pois a mediação presume que não há uma única história real e verdadeira; (ii) Abordagens pós-estruturalistas da narrativa permitem o exame da prática do relato na construção reflexiva do contexto no qual as histórias são contadas. Tal perspectiva focaliza a mediação como um todo, incluindo o mediador como coparticipante na construção da narrativa e na transformação do conflito (COBB, 1994; COBB e RIFKIN, 1991).

Cobb (1994) identifica três características da narrativa pertinentes à análise da mediação: coerência, fechamento e interdependência. Histórias de conflitos constroem ligações lógicas e causais entre atores, ações e resultados, atribuindo responsabilidades. Para que uma narrativa de conflito seja coerente é necessário haver unidade entre essas três características dentro de uma mesma história e em relação a outras narrativas.

A consolidação do significado de uma narrativa nunca é completo. Segundo Cobb (1994), o grau de coerência é uma função da 'completude' (closeness) narrativa. Essa característica é responsável por uma estrutura mais ou menos rígida das narrativas em mediação. As histórias de conflito são rígidas porque elas tendem a se autoperpetuar, são fechadas. Na mediação, as interpretações de uma narrativa são limitadas por papéis específicos e práticas locais. Embora o fechamento nunca seja completo, narrativas geram limitações de interpretação pela estabilização de elementos na narrativa. Desse modo, (i) mudanças no enredo desestabilizam a causalidade narrativa; (ii) mudanças de papéis desestabilizam posições de vítima e vitimizado; e (iii) mudanças no sistema de valores podem reorganizar o enquadre moral usado para avaliar ações. Tentativas de promover algumas dessas transformações são verificadas nas histórias dos reclamados em audiências 
de conciliação do Juizado Especial de Relações de Consumo. Qualquer desestabilização da primeira narrativa, feita pelo consumidor, pode significar uma posição mais favorável ao reclamado. Assim, fica claro que o lugar para a contestação, onde incoerências podem emergir, é no encadeamento causal e na relação de papéis e valores, pois a contestação é inevitável em mediação, na qual adversários refutam, negam e elaboram o contexto discursivo. Algumas narrativas, entretanto, são mais estáveis que outras e mais difíceis de serem contestadas. As mais completas seriam aquelas menos vulneráveis a interpretações alternativas e transformações e mais profundas em sua estrutura hierárquica (COBB, 1994).

A interdependência, por fim, se refere à regularidade com que adversários em uma mediação atribuem responsabilidade ao outro para os resultados negativos, de modo que há duas consequências discursivas: a construção de identidade como vítima e do outro como vitimizador, segundo Cobb (1994). Nós acrescentaríamos uma possibilidade discursiva alternativa, frequente nas audiências de conciliação, e também presente em Cobb (1994), que seria a atribuição de responsabilidade a alguém ou algo externo à audiência, como um problema no sistema de computadores ou a outra pessoa ausente, sobre a qual os adversários não teriam nem controle nem responsabilidade, constituindo mero infortúnio.

Nas narrativas de conflito, os papéis de vítima e de vilão são interdependentes. No interior de uma narrativa, a posição de vítima constrói a de vilão, através de um padrão narrativo constituído de sequências de explicação: acusações levam a justificativas e novas acusações. Nas narrativas de conflito, a interdependência dos personagens é mais visível nas sequências de explicação, pois reclamações e acusações (posição da vítima) são seguidas por justificativas, recusas e escusas. A interdependência de posições nas narrativas de conflito estabelece relações adversas, legitimando o "eu" e deslegitimando o outro, de modo que cada um alinha-se para construir uma posição favorável a si próprio. A resolução do conflito em mediação requer a intervenção de uma terceira parte para alterar a posição discursiva dos adversários e do processo, bem como gerar novos padrões de interação e uma nova interdependência (COBB, 1994).

As três características narrativas (coerência, completude, e interdependência) sugerem que os estágios do processo de mediação não podem sozinhos regular a transformação da narrativa de conflito porque (i) as histórias de conflito são construídas com diferentes graus de coerência; (ii) apresentam diferentes graus de completude e (iii) a evidência da interdependência narrativa, ou redundância interacional, sugere que contar as histórias de conflito reproduz o conflito, ao invés de resolvê-lo (COBB, 1994).

A incoerência de uma narrativa conduz à marginalização de um dos adversários e a um possível acordo desfavorável, por não contribuir para um bom esclarecimento que leve a um acordo na mediação. A regulação da construção da história pelo mediador, através de perguntas, facilita o desenvolvimento de uma narrativa completa e culturalmente plausível. Desse modo, mediadores precisam regular a construção de histórias considerando a sua coerência. Esse mandato acabaria com a distinção tradicional entre o processo de mediação e o conteúdo da disputa, pois, para regular o processo, mediadores devem gerenciar a construção do conteúdo (COBB e RIFKIN, 1991; COBB, 1994).

$\mathrm{Na}$ mediação das audiências de Conciliação do Juizado Especial de Consumo, a história do conflito é, geralmente, apresentada pela pessoa que fez a reclamação, isto é, 
pelo consumidor. Essa ordem, estabelecida por regras de procedimento jurídico, obedece a exigências éticas do sistema de mediação, que seria dar mais poder a quem entra na interação em desvantagem. Assim, o consumidor tem oportunidade de construir a história do conflito e o mediador pode restringir as possibilidades de contestação pelo adversário, caso a primeira história seja coerente.

\section{A CONSTRUÇÃO DO PAPEL DE VÍTIMA}

Quando o consumidor responde ao pedido inicial do mediador para contar a história do conflito, encontra-se, implicitamente, está um pedido de explicação sobre a sua presença no juizado e o motivo de sua reclamação. É nesse momento que ele tem oportunidade de tentar convencer o mediador de que o seu caso é realmente grave e a sua reclamação justa. Para isso, ele utiliza uma descrição bastante persuasiva do conflito, formulando o seu relato em termos extremos e se esforçando para construir para si a imagem de vítima e fazer legítima a sua reclamação. Esse esforço para legitimar a reclamação esclarece o uso excessivo de explicações durante a apresentação da história do conflito.

Hutchby \& Wooffitt (1998), ao escrever sobre a organização de explicações factuais, observa que, ao nos referirmos a um objeto ou a um estado de mundo, combinamos as palavras que podem ser legitimamente usadas. Assim, mesmo descrevendo coisas rotineiras, produzimos afirmações logicamente corretas ou uma lista final de afirmações legítimas. Heritage (1992), em um capítulo sobre "accounts e accounting", comentando a obra de Garfinkel (1967), observa o direcionamento inevitável que os atores sociais dão às suas próprias ações quando as explicam. Através de circunstâncias de elaborações indexicais e reflexivas, os atores sociais tentam determinar cada aspecto do sentido de uma explicação. Conscientes dos modos particularizados de elaboração circunstancial de enunciados que possam dar origem a problemas ou interpretações indesejadas, os atores "desenham" as suas explicações com respeito a uma gama de considerações e exigências. Assim, os atores fazem uso de um conhecimento comum dos possíveis usos e destinos de explicações em sala de aula, em corte judicial ou mesmo na performance de determinadas atividades como reclamar ou desculpar-se, por exemplo. Desse modo, notamos que o consumidor na audiência de conciliação do Juizado Especial de Relações de Consumo, usa procedimentos e razões táticas que direcionam a formulação do seu relato. Ele seleciona itens referenciais e faz afirmações descritivas de acordo com o objetivo de legitimar a sua reclamação, posicionando-se como vítima e posicionando o outro como vilão.

O Juizado é um ambiente propício de utilização de linguagem para garantir pontos de vista, perspectivas ou posições, já que o contexto de fala é de acusações, argumentações, contestações, enfim, de conflito. Em situações como estas, os falantes são sensíveis à probabilidade de recepção cética de suas afirmações ou possibilidade de respostas hostis. Então, eles utilizam recursos discursivos através dos quais os falantes podem garantir que as suas afirmações sejam entendidas como razoáveis e factuais, bem como constroem sentenças que antecipem e minimizem a efetividade de tipos específicos de contraafirmações, como faz o consumidor quando narra a sua história de conflito "(HUTCHBY \& WOOFFIT, 1988)" 
Potter (1996), citado em Hutchby e Wooffit (1998), propõe que a pesquisa em discurso factual se encaixe em duas categorias:

(i) orientação da ação: direciona para a pergunta "por que isso agora" que indicaria como sentenças factuais podem realizar tarefas interacionais e referenciais. Pois, mesmo descrições aparentemente neutras e sem intenções, podem ser usadas para executar uma gama de tarefas inferenciais sutis, objetivando estabelecer a validade de uma versão dos eventos.

(ii) Orientação epistemológica: seria o modo pelo qual uma explicação factual pode ser construída para garantir a existência objetiva de eventos ou objetos relatados, ou ainda para estabelecer a validade de afirmações que estão sendo feitas.

Esse último tipo de orientação examina propriedades sistemáticas que podem ser usadas para minimizar a possibilidade de que as afirmações feitas encontrem respostas céticas. Pois, há muitas circunstâncias cotidianas nas quais o status factual de uma explicação pode ser polêmico ou sujeito a ceticismo e refutação. Nesses casos, há uma variedade de práticas discursivas, através das quais, os falantes podem estabelecer o status factual e válido de suas afirmações. A seguir, veremos duas estratégias discursivas utilizadas pelo consumidor para legitimar a sua reclamação e posicionar-se como vítima.

\subsection{Formulação extrema}

Quando tentamos convencer as pessoas da validade de nossas opiniões, nos defendemos contra acusações ou reclamações, ou, mesmo tentando vender alguma coisa, estamos engajados em situações de persuasão. Segundo Hutchby \& Wooffitt (1998), nessas circunstâncias, tentamos fazer com que as pessoas com quem estamos falando cheguem a determinadas conclusões. Um recurso usado na persuasão é o modo como formulamos descrições. Um "estado de mundo", tal como uma opinião, uma desculpa ou uma reclamação, pode ser retratado como acreditável e digno de confiança, através do modo pelo qual a descrição é desenhada. Uma maneira de descrever é o que Pomerantz (1986) chamou de caso de formulação extrema, que seria um modo de nos referirmos a objetos ou eventos, envolvendo propriedades máximas ou mínimas, conforme mostraremos nas falas do consumidor ao narrar a sua história.

Em atos de fala tais como: acusação, defesa, justificativas e reclamação, Pomerantz (1986) observa que as formulações extremas são usadas para executar um entre três tipos de atividades: (i) pode ser usada contra possíveis desafios à reclamação ou à acusação que o falante está fazendo; (ii) pode ser usada por um falante que atribui causa, ou culpa, a um objeto ou uma pessoa; (iii) pode ser usada como uma avaliação moral de um estado de mundo ou de uma ação. O trabalho de Pomerantz (1986) é importante porque dá atenção ao modo pelo qual a atividade de persuadir pode ser conectada a uma variedade de circunstâncias rotineiras como reclamar, acusar, justificar, bem como enfatiza sutilmente as técnicas persuasivas que podem ser empregadas. Os participantes de uma interação não estão apenas tentando persuadir os seus coparticipantes, mas também estão "desenhando" a sua fala em antecipação a respostas céticas e não solidárias à causa defendida (HUTCHBY \& WOOFFITT, 1998). Assim, as pessoas produzem as suas versões do mundo, de modo 
que deem suporte ao tipo de ação conversacional em que elas estão engajadas, como veremos na fala dos consumidores ao explicar e narrar as suas histórias.

Exemplo 01 - (audiência: produto para colar retrovisor)

\begin{tabular}{|c|c|c|}
\hline 01 & Geraldo: & É o seguinte eu ia... viajando daqui pra Araçuaí(1.82) meu \\
\hline 02 & & retrovisor caiu na estrada, né? \\
\hline 03 & & Aí eu parei na na auto peças e pedi uma: (2.19) \\
\hline 04 & & um produto que se-fixasse o retrovisor interno. \\
\hline 05 & & $(1.28)$ \\
\hline 06 & & A menina me apresentou um um produto lá... \\
\hline 07 & & falou que era de fá: :cil acesso pra...manuseio \\
\hline 08 & & pra...coloca-botar no retrovisor... \\
\hline 09 & & comprei aquele negócio, \\
\hline 10 & & parei ne Ipatinga, \\
\hline 11 & & falaram que não podia viajar sem colocar \\
\hline 12 & & tinha que parar no mínimo três hora. \\
\hline 13 & & Aí eu parei na casa de uma cunhada minha em Ipatinga \\
\hline 14 & & $(1.28)$ \\
\hline 15 & & apliquei o produto, \\
\hline 16 & & não segurou nem um segundo \\
\hline 17 & & $(1.82)$ \\
\hline 18 & & e eu dormi lá em Ipatinga,viajei, né? no outro dia. \\
\hline 19 & & E...por isso que eu vim aqui. \\
\hline 20 & & O produto não segurou nem um segundo.(1.28) \\
\hline 21 & & Eu não acho justo eu pagar... \\
\hline 22 & & o valor que eu paguei é pouco \\
\hline 23 & & mas... eu não tive efeito nenhum, \\
\hline 24 & & se eu tivesse tido efeito pelo menos de uma hora, \\
\hline 25 & & eu não tive nem um segundo... \\
\hline 26 & & Apliquei conforme, conforme ta lá no no no...naquele: manual... \\
\hline 27 & & Não funcionou \\
\hline 28 & & $(1.28)$ \\
\hline 29 & & Então eu não concordo \\
\hline 30 & & $(1.55)$ \\
\hline 31 & & perder esse valor. \\
\hline 32 & & por um produto que não teve \\
\hline 33 & & $>$ não tive utilidade $<$ pra pra pra mim não teve utilidade. \\
\hline
\end{tabular}

Este excerto foi selecionado de uma audiência de conciliação, motivada em função da insatisfação do consumidor com um produto comprado por ele, em uma loja de peças e acessórios automotivos, com o objetivo de colar o retrovisor do seu automóvel.

Como de praxe, a audiência teve início com a mediadora, Denise, pedindo ao consumidor, Geraldo, que relatasse o que o levou àquela audiência. Dessa forma, Geraldo tem a oportunidade de convencer Denise da gravidade do seu problema e, para isso, ele usa uma descrição bastante persuasiva do conflito, usando termos extremos, que são repetidos várias vezes, para tornar mais convincente seu relato e se consolidar como vítima da situação. 
Ao narrar o que aconteceu, Geraldo procura convencer a mediadora de que ele foi enganado, uma vez que, de acordo com ele, comprou um produto sem utilidade; o consumidor enquadra a situação como uma reivindicação pelos direitos de consumidor lesado. Através da escolha lexical feita por Geraldo para se referir à cola que ele utilizou para tentar colar o retrovisor do seu automóvel, evidencia-se uma tentativa de fortalecer seu argumento a respeito da inutilidade da mesma. Ao se referir ao produto, ele nem mesmo utiliza seu nome, mas se refere a este dizendo "um produto lá..." (linha 06) e "aquele negócio" (linha 09), o que revela pouco caso e indiferença em relação ao produto.

Geraldo afirma que aplicou o produto (linha 15) e, para convencer os presentes de que o motivo de sua reclamação é justo, ele introduz em sua narrativa o uso de formulações extremas. A primeira delas "não segurou nem um segundo" (linha 16) é repetida duas vezes (linhas 20 e 25). Em seguida, ele utiliza outro termo extremo para confirmar a ineficácia do produto "eu não tive efeito nenhum" (linha 23).

Podemos perceber que o uso de formulação extrema associado ao uso da repetição é uma estratégia utilizada pelo consumidor para tornar seu argumento mais convincente. É como se repetindo várias vezes a mesma ideia, seu argumento ficasse mais forte e ele se sentisse mais acreditado na interação. Podemos perceber que o consumidor usa formulações extremas para fazer uma avaliação moral negativa da troca comercial que o levou a adquirir um produto ruim.

$\mathrm{Na}$ linha 26, ele antecipa uma possível acusação de não ter utilizado o produto de forma adequada e afirma ter aplicado o produto conforme a indicação do manual. Dessa forma, ele tira de sua responsabilidade a possibilidade de não ter utilizado o produto corretamente. Em seguida, utilizando novamente o recurso da repetição, ao dizer que discorda de pagar pelo produto (linhas 30-32), Geraldo está dizendo algo que já havia falado em momento anterior (linha 21). Consolidando o seu papel de vítima, mais uma vez ele repete o principal argumento da negociação que é a inutilidade do produto comprado (linhas 32-33). Ao argumentar tantas vezes que comprou um produto que foi totalmente ineficaz, Geraldo reclama para si a identidade de consumidor lesado, enganado, enquanto atribui a identidade de desonesto ao reclamado, por ter-lhe vendido tal produto.

O segundo exemplo de uso de formulações extremas foi retirado de uma audiência de conciliação, motivada pela insatisfação de uma cliente com um determinado banco, por ela ter cortado o seu dedo no momento em que fazia um depósito em um caixa de autoatendimento deste banco.

Exemplo 02 - (audiência: banco)

\begin{tabular}{|l|l|l|}
\hline 01 & Ana & e: foi um: transtorno pra mim, né? \\
02 & & ficar com esse: com esse dedo esse tempo todo. \\
03 & & Na outra audiência... tinha:: \\
04 & & $(1.18)$ \\
05 & & só uma se-uma: uma semana e pouca... \\
06 & & que.. já tinha cicatrizado... \\
07 & & Eu tive complicações e tudo.. \\
08 & & e foi uma coisa... traumatizante.. né? \\
\hline
\end{tabular}


Nessa audiência, o uso de termos extremos é utilizado em todo o relato. Ao narrar como se deu o corte em seu dedo, a consumidora tenta convencer a mediadora de que o que aconteceu com ela não foi um simples incidente, mas algo grave, e para isso ela usa um termo extremo para caracterizar a situação como um "transtorno" (linha 01). Feito isso, para tornar mais convincente seu relato, ela utiliza o sintagma adverbial "esse tempo todo" (linha 02) para mostrar a duração daquela situação. O incômodo não foi somente no dia do ocorrido, ele persistia até o dia da audiência. Ela também afirma que teve complicações e, logo depois, caracteriza a situação como "traumatizante" (linha 08), a fim de convencer a mediadora da validade de seus argumentos e da gravidade do ocorrido. Assim, as formulações extremas são usadas para atribuir culpa ao banco.

Exemplo 03 - (audiência: banco)

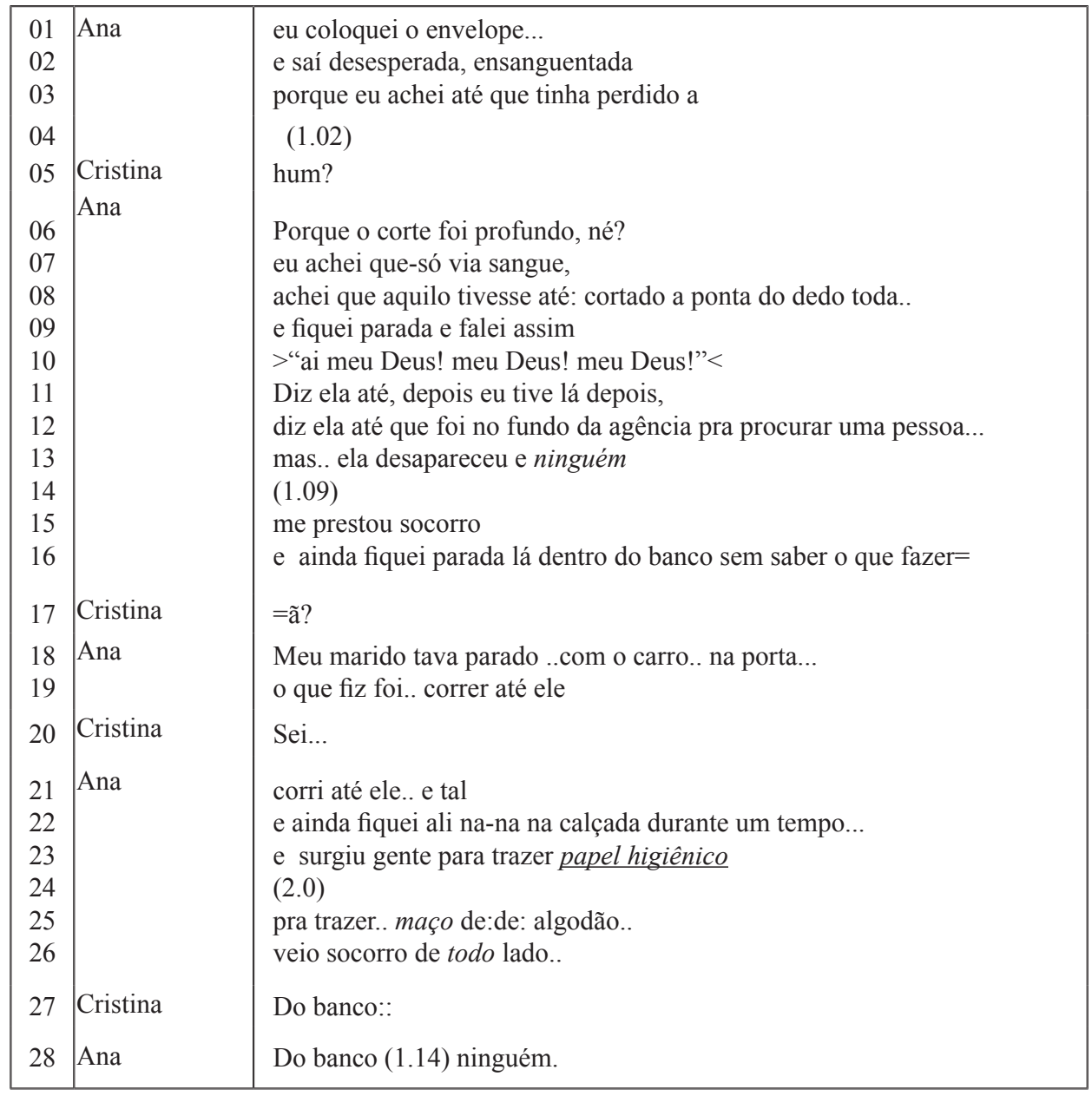


Neste momento da audiência, a consumidora relata como aconteceu o acidente e como ela agiu depois que se machucou. É interessante observar que os adjetivos que ela atribui a si mesma sinalizam o seu desejo de se firmar como vítima da situação e conseguir o alinhamento da mediadora.

Neste trecho, o uso de formulação extrema começa com os adjetivos "desesperada" e "ensanguentada" (linha 02), que evidenciam a seleção lexical estratégica da consumidora em escolher adjetivos de carga semântica bastante forte a fim de, mais uma vez, fortalecerse como vítima do conflito. Ela explica que o corte foi profundo (linha 06) e novamente utiliza um termo extremo "só via sangue" (linha 07), causando a impressão de algo extremamente grave. Ela diz, inclusive, que até pensou que tivesse cortado toda a ponta do seu dedo (linhas 08) e, com isso, ela tenta persuadir a mediadora da gravidade da situação.

Para demonstrar seu desespero, a consumidora utiliza o discurso reportado animando sua própria voz para tornar mais real sua agonia e mostrar como apelou gritando o nome de Deus (linha 10). Na sequência, Ana conta que, depois do ocorrido, ela voltou à agência e uma funcionária do banco disse que ela havia ido ao fundo da agência para procurar ajuda (linha 11-12); mas, utilizando novamente termos extremos, a consumidora afirma que a funcionária do banco "desapareceu" e que "ninguém" lhe prestou socorro (linhas 13-15).

Ana diz que, após o incidente, saiu do banco em direção ao seu marido, que estava de carro em frente ao banco, mas afirma ter ficado na calçada, em frente ao banco, por um tempo, antes de entrar no carro (linhas 18-22). Com isso, ela insinua que os funcionários do banco tiveram tempo suficiente para ajudá-la, mas, ainda assim, não o fizeram (linha 28). Dessa forma, a consumidora tenta invalidar a afirmação da funcionária do banco de que esta tentou lhe prestar socorro. A consumidora enquadra a situação como uma acusação por não ter sido socorrida pelos funcionários do banco.

A consumidora afirma que recebeu ajuda de outras pessoas, utilizando, para isso, outro termo extremo, que se constitui em um exagero "veio socorro de todo lado" (linha 26). Dessa forma, seu objetivo parece ser persuadir a mediadora de que o incidente que aconteceu com ela sensibilizou todas as pessoas que passavam na rua, e, ao mesmo tempo, provar que os funcionários tiveram tempo para socorrê-la, mas não o fizeram. Dito isso, a mediadora lhe pergunta sobre o banco e Ana afirma que ninguém do banco a socorreu. Dessa forma, ela culpa os funcionários do banco de não a terem ajudado por falta de vontade, não de tempo.

Observamos, nesse segundo exemplo, todos os três tipos de atividades que as formulações extremas podem executar, segundo Pomerantz (1986). Assim, notamos que a cliente diz que ficou na porta do banco após o acidente, prevenindo-se da justificativa de falta de tempo para socorrê-la. Ela evita um desafio à sua reclamação/acusação ao afastar a possibilidade de ser acusada de não ter dado tempo aos funcionários para socorrê-la ou de não ter aceitado ajuda. Todas as suas formulações são usadas com a finalidade de produzir uma acusação forte e atribuir culpa ao banco pelo acidente. Do mesmo modo, as suas formulações produzem uma avaliação moral negativa sobre o comportamento do banco e, consequentemente, dos seus funcionários que não se importam com os seus clientes, nem mesmo em um caso, no qual um deles tem um ferimento causado por uma máquina 
do banco.

A seguir, veremos como o consumidor, através de sua narrativa, identifica e atribui qualidades a si próprio e ao seu oponente, posicionando-se como vítima e enquadrando o outro como vilão.

\subsection{Categorias identitárias}

Quando descrevemos outras pessoas ou nós mesmos, há uma questão de seleção, já que muitas possibilidades de descrição são possíveis. Portanto, não há descrições neutras, elas são ricas em inferências, tendo em vista que fortes expectativas e convenções sociais e culturais estão associadas a elas. Categorias, não somente nos proveem com rótulos que nos permitem referir a pessoas, mas também fornecem recursos inferenciais através dos quais podemos entender e interpretar o comportamento descrito e designado pelas pessoas. Desse modo, categorias identitárias podem ser vistas como possuidoras de predicativos categóricos e locais para a imputação de expectativas convencionais, direitos e obrigações referentes a atividades esperadas ou apropriadas para uma dada categoria que se queira executar (HUTCHBY \& WOOFFITT, 1998).

Colocar uma pessoa ou colocar-se dentro de uma categoria significa que o conhecimento convencional sobre o comportamento é tão categorizado que pode envolver a interpretação das ações de si mesmo ou de outrem. Conhecimento tácito e expectativas sobre pessoas e suas ações são estocadas por referência a categorias conversacionais que serão relevantes para estabelecer explicações factuais válidas. Assim, a relação entre categorias, com suas expectativas e atividades associadas, é essencial na construção das afirmações dos falantes (HUTCHBY \& WOOFFIT, 1998; SACKS, 1992).

Como veremos nos exemplos de 04 a 08, há, no discurso do consumidor, inúmeras formas de se autoretratar e retratar o outro, dentro da história do conflito, a fim de justificar a sua reclamação, alinhar-se como vítima e posicionar o outro como vilão, além de conquistar o alinhamento do mediador.

Os exemplos 04 e 05 foram extraídos de uma audiência em que a consumidora, apesar de ter pedido o cancelamento da assinatura de uma determinada revista, continuou sendo cobrada nas faturas de seu cartão de crédito.

Exemplo 04 - (audiência: editora ABC)

\begin{tabular}{|l|l|l|}
\hline 01 & Marta: & depois dessa ligação e pedido de cancelamento, \\
02 & & a editora $\mathrm{ABC}$ mandou mais u- uma revista \\
03 & & eu não sei se foi a de: fevereiro ou a de março, \\
04 & & >na realidade $<$ \\
05 & & porque eu estava trabalhando em horário integral \\
06 & & e não tinh- \\
07 & & eu não tava nem tendo tempo de ler mais essas revistas também. \\
\hline
\end{tabular}

Este trecho foi retirado do primeiro relato da consumidora no qual ela teve a oportunidade de explicar o motivo que a levou a procurar o juizado especial. Nos turnos 
LADEIRA e DA SILVA - Estratégias discursivo-interacionais de construção de...

que precedem a este trecho, Marta relatou que era assinante da revista $\mathrm{X}$ e teve gratuidade na assinatura da revista $\mathrm{Y}$ por seis meses. Ela afirmou que não recebia as revistas pontualmente, mas que sempre havia atraso, ou às vezes ela nem as recebia. Disse também que recebeu um telefonema da editora $\mathrm{ABC}$ para a renovação da assinatura, mas que ela optou por não fazer a renovação devido aos atrasos das revistas. Depois disso, Marta disse que recebeu, em sua casa, uma carta comunicando que a assinatura das revistas já estava efetivada por um período de dois anos. Por causa desse fato, a consumidora ligou para a editora $\mathrm{ABC}$ e pediu o cancelamento das assinaturas.

No exemplo 04 acima, a consumidora afirma que, mesmo após o pedido de cancelamento, a editora ainda lhe enviou mais uma revista (linhas 02-03). Como uma forma de justificar o motivo pelo qual ela não queria mais ser assinante das revistas, ela define-se como uma pessoa muito ocupada, uma pessoa que trabalha em horário integral e, por isso, não dispõe de tempo para ler as revistas (05-07). Dessa forma, ela se categoriza como uma pessoa responsável, séria e trabalhadora.

No próximo exemplo, retirado da mesma audiência, a consumidora afirma ter ligado para o PROCON, a fim de ser instruída de como deveria agir naquela situação:

Exemplo 05 - (audiência: editora $\mathrm{ABC}$ )

\begin{tabular}{|l|l|l|}
\hline 01 & Marta: & E aí depois de ter vindo aqui pra saber como proceder, \\
02 & & eu aí liguei pro PROCON, \\
03 & & PROCON me au- me orientou a ta pagando \\
04 & & porque senão \\
05 & & eu que ficaria com meu nome \\
06 & & poderia ir pro SPC e pro SERASA \\
07 & porque eu estava tendo cobrança do cartão de crédito. \\
08 & Tomei todas as providências que me eram cabíveis, \\
09 & porque meu nome vale muito mais de trinta e dois reais e noventa.. \\
10 & & e continuei ligando \\
11 & & pedindo cancelamento \\
12 & e eu tenho os nomes todos relatados aí \\
13 & porque toda vez que eu liguei \\
14 & eu anotei o horário.. \\
15 & e não tive o cancelamento \\
\hline
\end{tabular}

Ao dizer que teve a orientação do PROCON para continuar pagando as faturas do cartão de crédito, sob pena de ter seu nome cadastrado no SPC e no SERASA (linhas 0106), Marta afirma ter tomado todas as providências que lhe eram cabíveis (linha 08), ou seja, ela continuou pagando as faturas do cartão de crédito, mesmo sem estar recebendo as revistas. Ela justifica essa sua atitude, afirmando que seu nome é muito mais importante que o valor pago pela revista (linhas 09) e se categoriza, desta forma, como uma pessoa honesta, digna, que faz questão de ter o nome limpo.

Os próximos exemplos $(06,07$ e 08) são de uma audiência motivada pela insatisfação da reclamante, locatária de um imóvel, com um ex-inquilino, visto que este saiu de seu imóvel deixando uma conta de luz pendente e ainda fez uma ligação elétrica ilícita, 22 
utilizando a energia diretamente da rua, sem ser contabilizada pelo padrão (gato).

Exemplo 06 - (audiência: conta de energia elétrica)

\begin{tabular}{|l|l|l|}
\hline 01 & Maria & Pois é, ue não é possível \\
02 & & se eu tiver que pagar mais essa conta dos outros \\
03 & & eu num vou acreditar \\
04 & & que vai ter mais mais mais mais justiça nesse mundo. \\
\hline
\end{tabular}

Este excerto foi selecionado da primeira parte da audiência, em que a consumidora expõe os motivos que a levaram àquele setor de conciliação. É importante ressaltar que o reclamado (o inquilino) não compareceu à audiência e, dessa forma, parece ser mais fácil para a reclamante se estabelecer no papel de vítima do conflito, uma vez que o reclamado não está presente para dar sua versão dos fatos.

Ao dizer que "não é possível (...) pagar mais essa conta dos outros" (linhas 01-02), Maria deixa subentendido que esta não é a primeira vez que ela tem um prejuízo como este. Assim, ela constrói uma imagem de pessoa ingênua e inocente que, por mais de uma vez, teve que pagar uma conta que não é dela. Na sequência, ela diz que se tiver que pagar aquela conta, não vai mais acreditar que existe justiça no mundo. Ao dizer essas palavras, surge a identidade de pessoa injustiçada, ao mesmo tempo em que ela reafirma a sua posição de vítima do conflito.

Nessa mesma audiência, a empresa de energia elétrica atribui a responsabilidade pela conta de luz à reclamante, uma vez que o contrato de fornecimento de energia elétrica estava em nome da proprietária do imóvel, conforme pode ser observado no exemplo abaixo:

Exemplo 07 - (audiência: conta de energia elétrica)

\begin{tabular}{|l|l|l|}
\hline 01 & Maria & Mas eu não imaginava \\
02 & & que ele ia mexer no relógio, \\
03 & & eu só queria ver ele \\
04 & & que eu queria falar pra ele \\
05 & & que se ele quisesse roubar \\
06 & & ele subisse no poste lá na rua \\
07 & & e pegasse lá direto da Cemig, \\
08 & & não de mim, \\
09 & & porque tá roubando de mim, ue, \\
10 & & eu sou pobre, \\
11 & & eu num posso ficar pagando conta dos outros não. \\
\hline
\end{tabular}

Ao ouvir da mediadora que ela deveria ter passado o contrato em nome do inquilino, Maria tenta se justificar dizendo que não imaginava que ele iria mexer no relógio (linha 01-02). Ao dizer isso, Ana "Maria" se define, mais uma vez, como uma pessoa ingênua, de boa índole e que confia no outro. 
Em seguida, ela diz que gostaria de se encontrar com o reclamado (este não compareceu à audiência) e dizer a ele que se fosse para ele roubar, que ele roubasse da CEMIG e não dela, porque ela é uma pessoa pobre e não tem como pagar as contas dos outros (03-11). Assim, ela se autocategoriza como alguém com poder aquisitivo muito baixo e incapaz de pagar aquela conta de luz, ao mesmo tempo em que categoriza o reclamado como uma pessoa de má índole, um ladrão.

Neste próximo exemplo, a autocategorização da consumidora se dá através do recurso da repetição, que é utilizado em todos os turnos:

Exemplo 08 - (audiência: conta de energia elétrica)

\begin{tabular}{|l|l|l|}
\hline 01 & Maria & Que que ele fez, \\
02 & & eu não tenho condição de ficar pagando conta dos outros. \\
03 & & Outro dia eu fiz uma assinatura na na oi com a moça \\
04 & & a moça me deu bastante calote \\
05 & & agora eu to pagando a oi, \\
06 & & ah to cansada de pagar conta dos outros! \\
\hline
\end{tabular}

Cada fala de Maria constitui-se em repetir algo que já foi falado nos turnos anteriores, a fim de enfatizar as identidades que a favorecem como vítima do conflito. Novamente, ela diz que não tem condições financeiras de pagar a conta de energia (linha 02), categorizando-se como uma pessoa com baixo poder aquisitivo e incapaz de efetuar aquele pagamento. Em seguida, ela relata outra situação em que teve prejuízo (linhas 03-05), reforçando a sua posição de vítima e conclui sua fala dizendo estar cansada de pagar a conta dos outros (linha 06). Novamente, Maria se autoidentifica como uma pessoa inocente e de boa índole, que acredita no outro.

Podemos observar que, em situações de conflito, as categorizações são interdependentes, ou seja, autocategorização implica em categorização do outro. Quando os consumidores se categorizam como honestos, de boa índole, ingênuos e pobres, eles estão categorizando os outros como pessoas que tiram vantagem de pessoas ingênuas e honestas, isto é, classificam o outro em uma categoriza oposta à sua.

\section{CONSIDERAÇÕES FINAIS}

Este artigo procurou mostrar como o consumidor, participante de mediações em um juizado especial de relações de consumo, representa e constrói sua identidade discursiva através de atividades de narrar e explicar a história do conflito em quatro audiências de conciliação. Examinamos como os consumidores elaboram suas estórias e como eles apresentam e representam discursivamente suas múltiplas identidades em função do propósito comunicativo de posicionar-se como vítimas e de posicionar o outro como vilão da história do conflito. Portanto, a perspectiva deste trabalho é que a fala é ação sucinta e que, ao estudar as falas, estudamos as ações dos participantes, a partir das quais se 
coconstroem identidades. As narrativas se apresentam como o meio que os participantes utilizam para construir e negociar suas identidades.

A análise da fala-em-interação entre consumidor, reclamado e mediador revelou as estratégias discursivas utilizadas pelos consumidores durante as audiências de conciliação, realizadas através dos fenômenos de: uso de explicações (accounts) como recurso discursivo do consumidor para prevenir inferências negativas a seu respeito, uso de termos extremos para fortalecer seus argumentos e torná-los mais persuasivos; o uso de diferentes categorias identitárias como "pessoa honesta", "pessoa de boa índole", com o objetivo de se firmar como vítima do conflito e também o uso de um grande número de repetições, o que evidencia uma tentativa de fortalecer seus argumentos e persuadir a mediadora a seu favor. a fim de que seu objetivo seja alcançado na audiência.

Os recursos usados no relato do conflito pelo consumidor são semelhantes a narrativas de fatos sobrenaturais, nas quais os contadores utilizam estratégias discursivas específicas, a fim de se protegerem, por antecipação, de alguma reação cética às suas histórias. Ao notarmos que os consumidores usam esses mesmos recursos, sugerimos que eles não estão em uma situação confortável na formulação de suas reclamações em audiências do Juizado Especial Cível de Relações de Consumo. Podemos observar que muitos esforços discursivos são empregados pelo consumidor, com a finalidade de tornar justa e legítima a sua reclamação.

\section{$\overline{\text { REFERÊNCIAS BIBLIOGRÁFICAS }}$}

BASTOS, L.C. (2008). Estórias, vida cotidiana e identidade: uma introdução ao estudo da narrativa. In: Carmem Rosa Caldas-Coulthard; Leonor Scliar Cabral (org.). Desvendando o Discurso: homenagem a Malcolm Coulthard. Florianópolis: ed. UFSC, p. 79-111.

BERGER, P. L.; LUCKMAN, T. (1985). A construção social da realidade. Petrópolis, RJ: Vozes.

COBB, S. (1994). A narrative perspective on mediation: toward the materialization of the 'storytelling metaphor'. In: FOLGER, J.P.; JONES, T.S. (eds.). New directions in mediation: communication research and perspectives. Thousand Oaks, CA: Sage Publications, p. 48-63.

COBB, S.; RIFKIN, J. (1991). Neutrality as a discursive practice: the construction and transformation of narratives in community mediation. In: SARAT, A.; SILBEY, S. (Eds.). Studies in Law, politics and society. Greenwich, CT: Jai Press, v. 11. p. 69-94.

GARFINKEL, H. (1967). Studies in Ethnomethodology. Englewood Cliffs, NJ: Prentice Hall, 288 p.

GOFFMAN, E. (1980). A elaboração da face. In: Figueira, s. (org.). Psicanálise e Ciências Sociais. Rio de Janeiro: Francisco Alves, p. 76-114. . (1999). A representação do eu na vida cotidiana. $8^{\text {a }}$.ed. Petrópolis: Vozes.

GUMPERZ, J.J. (1998). Convenções de contextualização. In: RIBEIRO, B.T.; GARCEZ, P.M. (orgs.). Sociolinguística Interacional: antropologia, lingüistica e sociologia em análise do discurso. Porto Alegre: AGE, p. 98-119.

HERITAGE, J. (1992). Accounts and Accountings. In: Garfinkel and Ethnomethodology. Cambridge: Polity Press, p. 135-178. 
LADEIRA e DA SILVA - Estratégias discursivo-interacionais de construção de...

HUTCHBY, I.; WOOFFITT, R. (1998). Conversation analysis: principles, practices and applications. Cambridge: Polity.

LADEIRA, W. T. (2005). O papel do mediador no gerenciamento e negociações de conflitos em audiências de conciliação. 2005. 220 f. Tese (Doutorado em Letras). Departamento de Letras, Pontifícia Universidade Católica do Rio de Janeiro, Rio de Janeiro.

LABOV, W. (1982). Speech actions and reactions in personal narrrative. In: TANNEN, D. (ed.). Analyzing discourse: text and talk. Washington (DC): Georgetown University Press, p. 219-247.

LITTLEJOHN, S.W. (1982). Teorias de Comunicação Interpessoal. S.W. LITTLEJOHN. Fundamentos Teóricos da Comunicação Humana. Trad. Álvaro Cabral. Rio de Janeiro: Zahar Ed., p. 205-252.

POMERANTZ, A. (1986). Extreme Case Formulations: a way of legitimizing claims. Human Studies, n. 9, p. 219-229.

POTTER, J. (1996). Representing Reality: discourse, rhetoric and social construction. London: Sage Publications.

SACKS, H. (1992). Lectures on conversation. Oxford: Blackwell.

Recebido: 20/08/2009

Aceito: $11 / 04 / 2011$ 